\title{
Development of oral hydrocortisone granules with taste masking for the treatment of neonates and infants with adrenal insufficiency
}

\author{
Martin Whitaker ${ }^{1}$, Dena Digweed ${ }^{2}$, Sarah Spielmann ${ }^{3}$, Hiep Huatan ${ }^{2}$, David Eckland ${ }^{2}$, Oliver Blankenstein ${ }^{3}$, Heiko Krude $^{3}$, Richard Ross $^{1}$
}

${ }^{1}$ The University of Sheffield, Sheffield, UK; ${ }^{2}$ Diurnal Limited, Cardiff, UK; ${ }^{3}$ Charité Universitätsmedizen Berlin, Germany

\section{Background}

Current treatment in Europe for adrenal insufficiency in neonates and infants is unsatisfactory as unlicensed adult dosage formulations are used. These are difficult to administer and may give rise to inconsistencies in dose as the content uniformity of the dosage form cannot be verified. As there is no licensed hydrocortisone formulation for children $<6$ years hydrocortisone is often compounded by pharmacies using adult hydrocortisone tablets. In a recent study of compounded hydrocortisone up to $20 \%$ of the batches did not meet European Pharmacopeial accuracy and precision criteria (ECE 2014 Abstract \#1278). This medication safety study investigated hydrocortisone individually and extemporaneously compounded for paediatric use in adrenally insufficient patients, meaning the current therapy is inadequate in up to every $5^{\text {th }}$ child treated. Thus, there is a need for specifically designed and licensed hydrocortisone formulations for this vulnerable paediatric patient group especially neonates and infants.
\end{abstract}

\section{Methods}

Infacort ${ }^{\circledR}$ is a newly developed immediate release formulation of hydrocortisone that is provided in child appropriate unit dosage units $(0.5,1,2$ \& $5 \mathrm{mg}$ ) of multi-particulate granules. The granules are designed with a taste masking layer to permit compliant oral dosing. The objective of this study was to evaluate the pharmacokinetic performance of Infacort $^{\circledR}$ and its safety in dexamethasone suppressed adult volunteers. $\quad$ Infacort $^{\circledR}$ exposure was compared to the adult immediaterelease dosage form, hydrocortisone 10 $\mathrm{mg}$ tablets. This was a single centre, open-label, randomised crossover study in 16 dexamethasone suppressed healthy adults. The study was approved by the South East Wales Research Ethics Committee and each potential study subject provided their freely given informed consent. EudraCT number: 2013-000260-28

Figure 1: Cross-sectional diagram of a multi-layered $\quad$ Infacort $^{\circledR}$ granule formulation

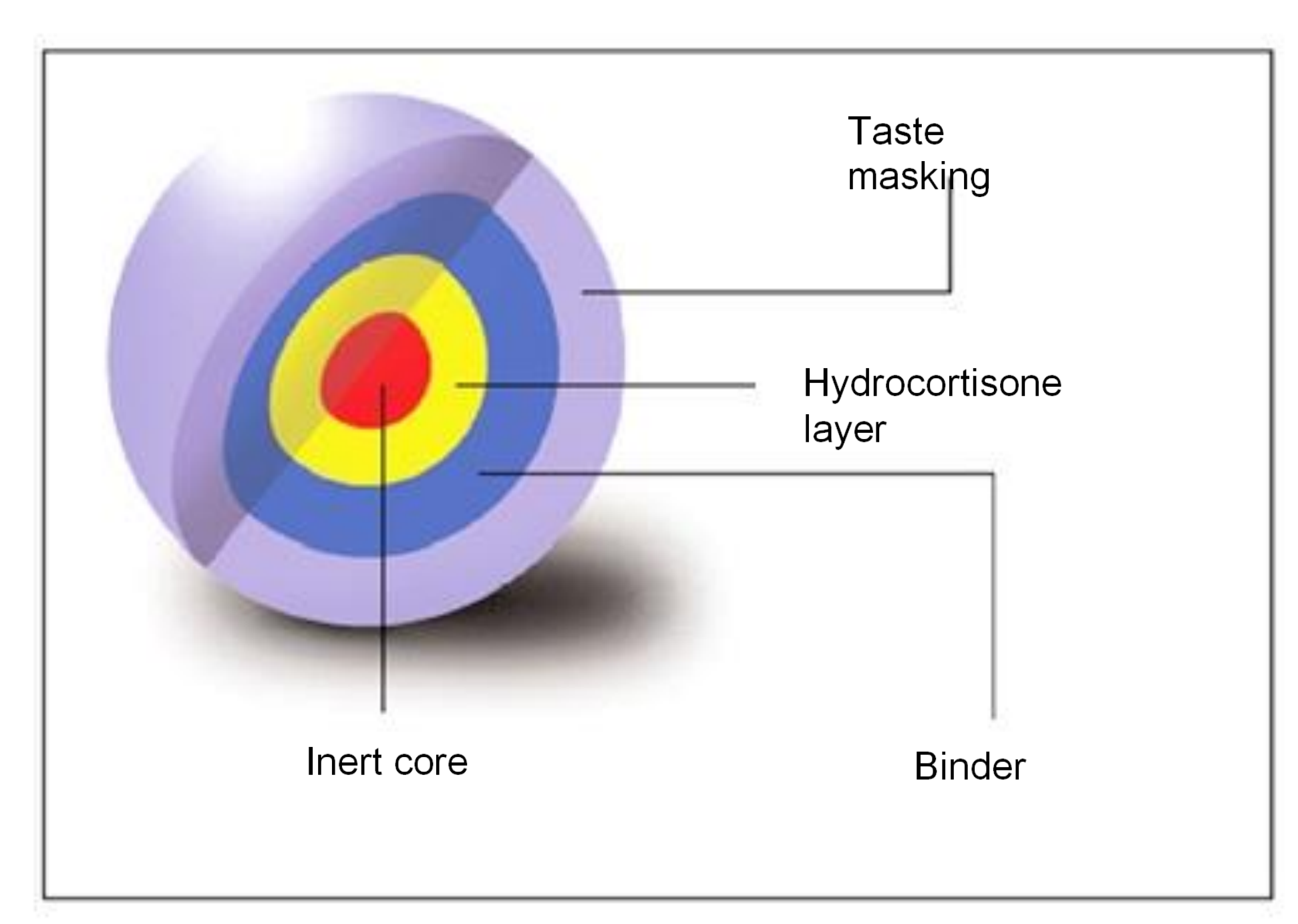

\section{Results}

Infacort ${ }^{\circledR}$ and hydrocortisone tablets were administered to subjects at 07:00 (fasted) with $200 \mathrm{~mL}$ water. Blood samples were taken at hourly intervals for 12 hours and serum cortisol concentration was determined by tandem mass spectrometry LC-MSMS (Applied Biosystems, US). Pharmacokinetic end-points were derived from the individual serum cortisol concentration-time data using WinNonlin Phoenix 32.

Infacort ${ }^{\circledR}$ and hydrocortisone tablets at a dose of $10 \mathrm{mg}$ are bioequivalent as reflected by the geometric LSmean $90 \% \mathrm{Cl}$ for ratios of $\mathrm{Cmax} \mathrm{AUC}_{0-\mathrm{t}}$ and $\mathrm{AUC}_{0 \text {-inf }}$ within $0.8-1.25$. The majority of subjects described Infacort ${ }^{\circledR}$ as, "not good or bad", for smell ( $81.3 \%$ to $87.5 \%$ of subjects), feel in the mouth (68.8 \% of subjects) and taste (68.8 \% to $81.3 \%$ of subjects) using a palatability questionnaire

Figure 2: Comparison of the cortisol pharmacokinetic profile between $10 \mathrm{mg}$ hydrocortisone tablet $(\mathrm{HC})$ and $10 \mathrm{mg}$ Infacort $^{\circledast}(\mathrm{n}=16)$

Figure 3: Dose-response to $0.5 \mathrm{mg}-10 \mathrm{mg}$ Infacort $^{\circledR}$ in dexamethasone suppressed healthy volunteers $(n=16)$
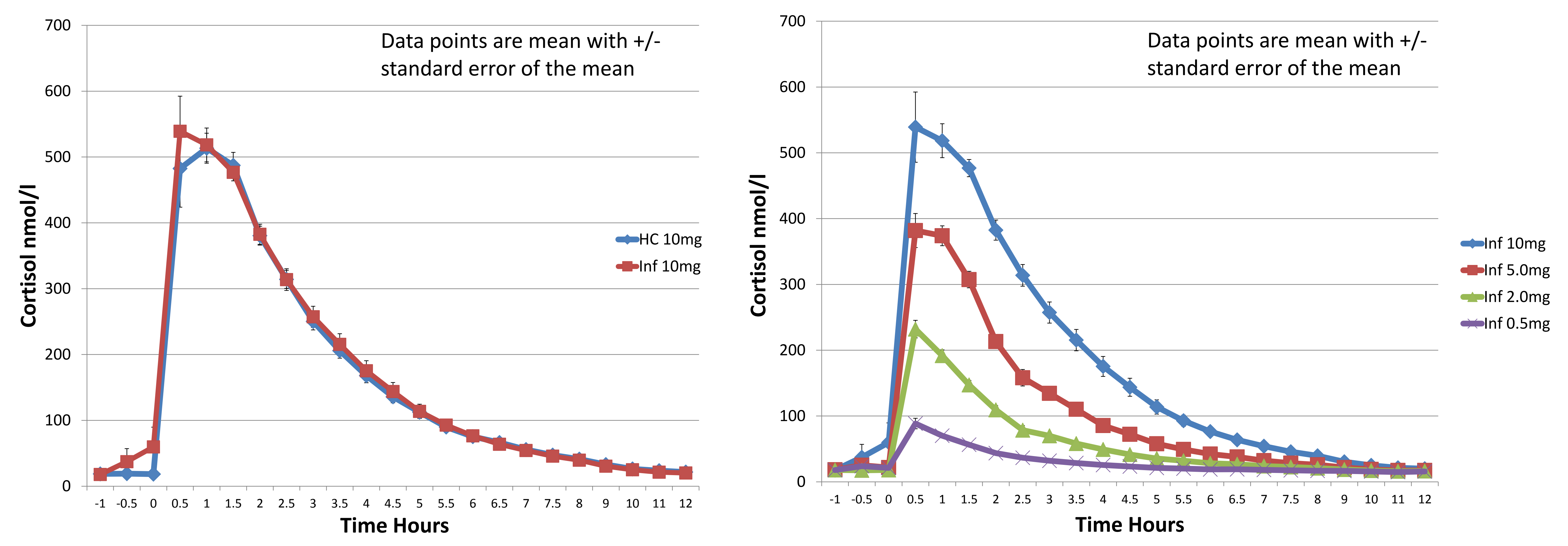

Table 1: Bioequivalence of $10 \mathrm{mg}$ Infacort ${ }^{\circledR}$ to $10 \mathrm{mg}$ Hydrocortisone Tablets

\begin{tabular}{|l|c|c|c|}
\hline $\begin{array}{c}\text { Infacort } \\
\text { Geomean }\end{array}$ & $\begin{array}{c}\text { Hydrocortisone Tablets 10mg } \\
\text { Geomean }\end{array}$ & $\begin{array}{c}\text { Ratio Infacort }{ }^{\oplus} \text { to Hydrocortisone } \\
\text { (90\% Confidence Interval) }\end{array}$ \\
\hline $\mathrm{C}_{\max }(\mathrm{nmol} / \mathrm{l})$ & 566 & 598 & $95(84-107)$ \\
\hline $\mathrm{AUC}_{0 \text {-inf }}\left(\mathrm{hr}^{*} \mathrm{nmol} / \mathrm{l}\right)$ & 1602 & 1576 & $101(96-107)$ \\
\hline $\mathrm{T}_{\max (\mathrm{hr})}$ & 0.75 & 1.00 & $0.0(-0.5-0.3)$ \\
\hline
\end{tabular}

Figure 4: Dose linearity (AUC) from 0.5 to $10 \mathrm{mg}$ Infacort $^{\circledR}$

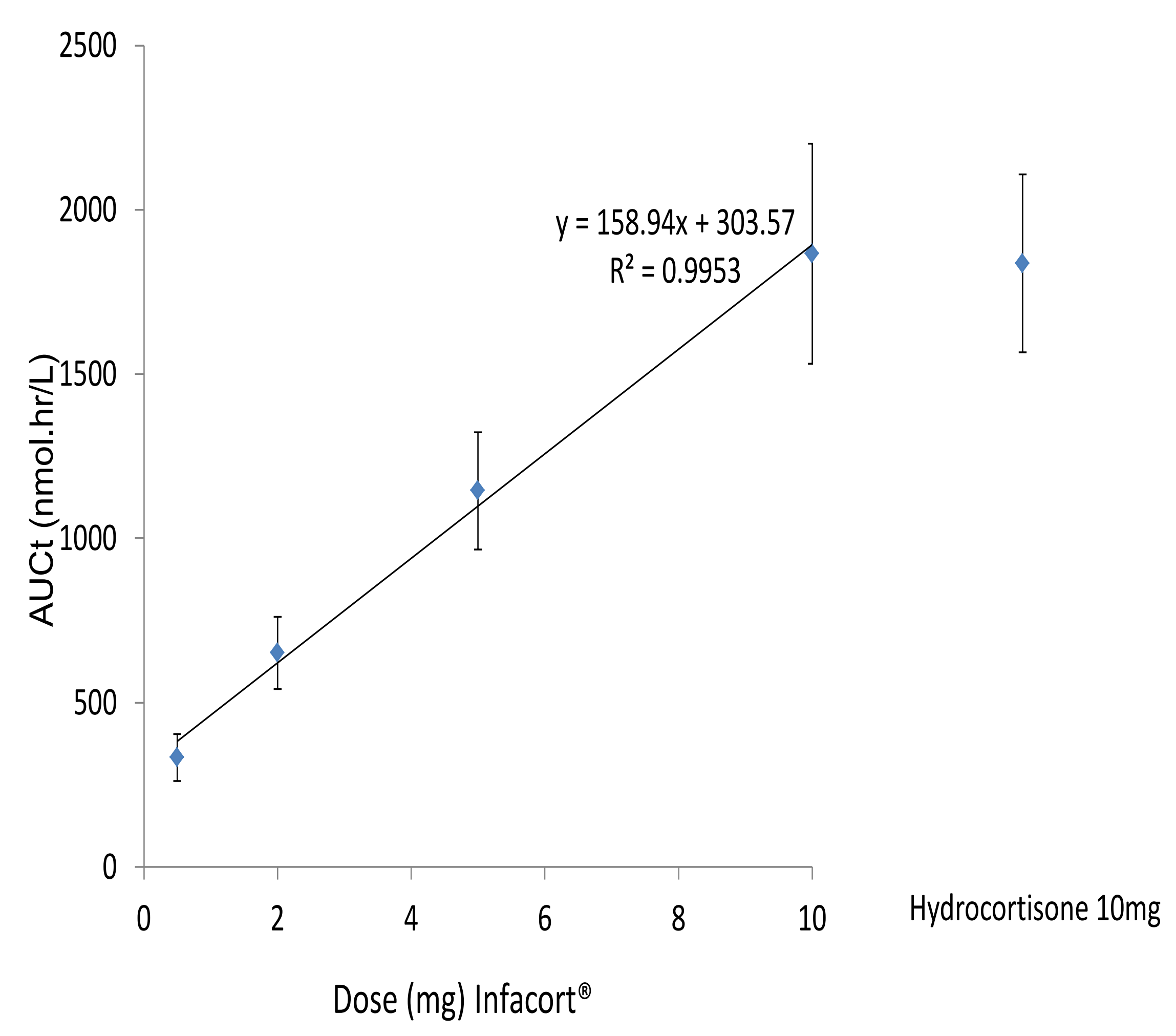

\section{Conclusions and Discussion}

Infacort ${ }^{\circledR}$ was safe, well tolerated and of neutral taste when administered as a single oral dose of $10 \mathrm{mg}$. Infacort ${ }^{\circledR} 10 \mathrm{mg}$ was bioequivalent to $10 \mathrm{mg}$ hydrocortisone tablets with respect to $\mathrm{C}_{\max }$ and $\mathrm{AUC}$. Infacort ${ }^{\circledR}$ demonstrated dose-linearity between 0.5 $\mathrm{mg}$ and $10 \mathrm{mg}$.

Infacort ${ }^{\circledR}$ has the potential to be the first, regulatory approved, specially developed paediatric formulation for the treatment of children suffering from adrenal insufficiency under 6 years of age in Europe. The study was performed under a Paediatric Investigation Plan approved by the European Medicines Agency (EMEA-001283-PIP01-12) and further studies in the target patient group are planned. 